Revista Eletrônica do Mestrado em Educação Ambienta1

Revista do PPGEA/FURG-RS

ISSN $1517-1256$

Programa de Pós-Graduação em Educação Ambiental

\title{
Sustentabilidade Complexa: o discurso de sustentabilidade sob a perspectiva do Pensamento Complexo de Edgar Morin
}

\author{
Jean Carlos Mendes da Rocha ${ }^{1}$ \\ Universidade Estadual de Londrina/Instituto Federal do Paraná \\ https://orcid.org/0000-0003-3349-4660 \\ Luís Miguel Luzio-dos-Santos ${ }^{2}$ \\ Universidade Estadual de Londrina \\ https://orcid.org/0000-0001-9369-0298
}

\begin{abstract}
Resumo: A partir da análise do discurso dominante de sustentabilidade (de Brundtland), este artigo tem por objetivo apresentar uma proposta alternativa a ele, tendo como perspectiva a Teoria do Pensamento Complexo de Edgar Morin. Diante dos problemas engendrados pelo atual modelo de desenvolvimento, destacamos que o discurso de sustentabilidade de Brundtland segue a mesma lógica que levou à humanidade a uma série crise, por isso tem se mostrado insuficiente para compreender e atender a complexidade dos problemas socioambientais atuais. Como resposta, propomos uma reflexão construída sob a perspectiva da sociedade e do meio ambiente, orientada por novos valores e saberes: a sustentabilidade complexa. Além das dimensões clássicas, social, ambiental e econômica, a sustentabilidade complexa incorpora ao discurso de sustentabilidade quatro outras dimensões: a política, a cultural, a espacial e a interior.
\end{abstract}

Palavras-chave: Sustentabilidade. Pensamento Complexo. Edgar Morin.

\section{Sostenibilidad compleja: el discurso de La sostenibilidad desde la perspectiva Del}

\section{pensamiento complejo de Edgar Morin}

Resumen: A partir del análisis del discurso de sostenibilidad dominante (por Brundtland), este artículo tiene como objetivo presentar una propuesta alternativa, con la perspectiva de la Teoría del pensamiento complejo de Edgar Morin. En vista de los problemas engendrados por el modelo de desarrollo actual, destacamos que el discurso de sostenibilidad de Brundtland sigue la misma lógica que condujo a la humanidad a una serie de crisis, por lo que ha demostrado ser insuficiente para comprender y abordar la complejidad de los problemas socioambientales actuales. Como respuesta,

\footnotetext{
${ }^{1}$ Mestrando do Programa de Pós-Graduação em Administração da Universidade Estadual de Londrina. Administrador no Instituto Federal do Paraná, Campus Londrina. Londrina/Paraná, Brasil. e-mail: jean.rocha@ outlook.com

${ }^{2}$ Doutor em Ciências Sociais (PUC-SP), graduado em Economia e Administração (UEL), Professor do Departamento de Administração da UEL. Londrina/Paraná, Brasil. e-mail: 1mig@uol.com.br
}

Rev. Eletrônica Mestr. Educ. Ambient. Rio Grande, v. 37, n. 1, p. 208-227, jan/abr. 2020.

E-ISSN 1517-1256 
proponemos una reflexión construida desde la perspectiva de la sociedad y el medio ambiente, guiada por nuevos valores y conocimientos: sostenibilidad compleja. Además de las dimensiones clásicas, sociales, ambientales y económicas, la sostenibilidad compleja incorpora al discurso de la sostenibilidad otras cuatro dimensiones: política, cultural, espacial e interior.

Palabras clave: Sostenibilidad. Pensamiento Complejo. Edgar Morin.

\title{
Complex Sustainability: the sustainability discourse from the perspective of Edgar Morin's Complex Thought
}

\begin{abstract}
Based on the analysis of the dominant sustainability discourse (by Brundtland), this article aims to present an alternative proposal to it, with the perspective of Edgar Morin's Complex Thought. In view of the problems engendered by the current development model, we highlight that Brundtland's sustainability discourse follows the same logic that led humanity to a serious crisis, which is why it has proved to be insufficient to understand and address the complexity of current socio-environmental problems. As an answer, we propose a reflection built from the perspective of society and the environment, guided by new values and knowledge: complex sustainability. In addition to the classics dimensions, social, environmental and economic, complex sustainability incorporates into the sustainability discourse four other dimensions: political, cultural, spatial and interior.
\end{abstract}

Keywords: Sustainability. Thought Complex. Edgar Morin.

\section{Introdução}

Ao contestar os pilares fundamentais do modelo de desenvolvimento capitalista, o discurso da sustentabilidade vem ganhando um importante papel na sociedade atual. Tal modelo, baseado no consumo alienado e no acúmulo desenfreado de riqueza nas mãos de um número reduzido de atores, tem provocado processos de devastação ambiental e social sem precedentes, sobrecarregando os sistemas ecológicos, aumentando a polarização social e os conflitos em todo o mundo. Por esses motivos, vem caindo o discurso do crescimento ilimitado como medida de progresso, que desconsidera os limites naturais do planeta e os impactos nocivos gerados sobre parte significativa das sociedades humanas (HOPWOOD; MELLOR; O'BRIEN, 2005; LUZIO-DOS-SANTOS, 2015; BELCHIOR; VIANA, 2017).

A dinâmica desse modelo faz com que o homem explore a natureza, numa visão antropocêntrica, como se estivesse descolado dos demais ecossistemas e estes só se justificassem para servi-lo, ameaçando a sustentabilidade da vida nas suas diferentes expressões. De acordo com Moore (2017), a humanidade se forma através e não separada da teia da vida. Logo, não existe a separação da natureza em nossa experiência de vida. Essa perspectiva coloca por terra a ideia de linearidade e de hierarquia, entendendo a realidade a partir da metáfora da teia, substituindo a visão centrada nas partes para entendê-la a partir das inter-relações e das conexões que se estabelecem e formam um todo 
inseparável. Diferentemente do modelo de desenvolvimento capitalista, em que o desenvolvimento técnico e econômico passa a dominar a natureza e boa parte da humanidade, subordinando tudo e todos aos seus interesses de acumulação infinita sem preocupação com as consequências espaciais e temporais (MORIN, 2013).

A aposta contínua nesse modelo desenvolvimentista levou a humanidade a uma situação extremamente preocupante. Nos últimos séculos, os efeitos da interferência dos seres humanos no ambiente global aumentaram de maneira considerável. Segundo Crutzen (2002), a população humana aumentou dez vezes, passando para mais de 7 bilhões de pessoas, o desmatamento cresceu de maneira assustadora, totalizando $294 \mathrm{mil} \mathrm{km} \mathrm{km}^{2} \mathrm{em}$ 2017 (área equivalente ao território italiano), contribuindo para a redução da biodiversidade e para processos de desertificação em todo o planeta. Além disso, a crescente expansão da agricultura, da pecuária e da queima de combustíveis fósseis têm contribuído para aumentos substanciais na concentração de gases de efeito estufa, ocasionando, entre outras consequências, o aquecimento climático. Esses fatores são agravados pelas iniquidades econômicas que, ao mesmo tempo, em que conseguiram aumentar a renda per capita mundial em dez vezes nos últimos cem anos, aceleraram de forma desproporcional a concentração de renda, o desemprego, a violência e a pobreza.

O primeiro alerta sobre essa crise mundial foi dado no final dos anos 1960 e início dos anos 1970. Dados científicos apontaram a gravidade dos problemas ambientais e a necessidade de se repensar o futuro da humanidade. O debate sobre sustentabilidade começa com a tese dos limites do crescimento e a primeira Conferência das Nações Unidas sobre Meio Ambiente Humano em Estocolmo, em 1972. Em seguida, sucederam-se uma série de eventos que destacaram a dimensão global da crise ambiental, o problema energético e a crise do capitalismo, que culminaram na criação da Comissão Mundial sobre Meio Ambiente e Desenvolvimento (1983), na ONU, cujo trabalho ficou conhecimento como “Relatório de Brundtland”, em 1987 (DOVERS, 1996; PIERRI, 2001).

Com esse relatório, avançaram discussões em torno de um novo paradigma de desenvolvimento, o desenvolvimento sustentável. Tais esforços eram uma tentativa de conciliar preservação ambiental, com vigor econômico e equidade social, numa ideia centrada na satisfação das necessidades da geração atual, sem comprometer a capacidade das gerações futuras de satisfazerem as suas próprias necessidades. Apesar do discurso de sustentabilidade de Brundtland, no seu sentido mais amplo e normativo, ter sido amplamente aceito e adotado por milhares de organizações em todo o mundo, ele é muito criticado por sua falta de clareza. O que torna o campo discursivo da sustentabilidade uma Rev. Eletrônica Mestr. Educ. Ambient. Rio Grande, v. 37, n. 1, p. 208-227, jan/abr. 2020. 
arena difusa e conflituosa (GLADWIN; KENNELLY; KRAUSE, 1995). Hoje, esse discurso tem ganhado cada vez mais relevância na nossa sociedade e tem indicado uma mudança na compreensão das relações da humanidade com a natureza e entre as pessoas (HOPWOOD; MELLOR; O'BRIEN, 2005).

Emerge nesse contexto o Pensamento Complexo, com uma proposta alternativa de pensar a realidade e analisar as questões socioambientais que envolvem o discurso de sustentabilidade. A complexidade tem por desafio instituir outra forma de enxergar o mundo e a natureza que o constitui, buscando a proteção ambiental e social, através de uma resposta capaz de reformular e repensar a relação sociedade/natureza a partir de um equilíbrio dinâmico (BALIM; MOTA; SILVA, 2014). Segundo Morin, a complexidade tem por desafio superar as carências e insuficiências do pensamento moderno (cartesiano e simplista), que mais fragmenta e mutila o conhecimento, do que exprime a realidade. $\mathrm{O}$ Pensamento Complexo anseia um conhecimento transdisciplinar, aberto, não fragmentado, não reducionista, capaz de unir e solidarizar conhecimentos separados e despertar a responsabilidade que daí manifesta-se (MORIN, 2015; 2018).

Uma das grandes críticas da complexidade em relação ao pensamento moderno é a visão reducionista e determinista com que este procura entender a realidade. Segundo Luzio-dos-Santos (2017), Descartes, um dos principais percursores do pensamento moderno, procurou encontrar leis universais e regularidades que possibilitariam o controle e dominação do homem sobre a natureza. Separando o sujeito pensante e o objeto, ele criou os fundamentos do paradigma simplificador, que apoiado no cálculo, passou a dividir a realidade em partes, fragmentando e hiperespecializando o conhecimento, na busca por objetividade e regularidades estendidas a todos os fenômenos, numa visão estritamente mecanicista.

É importante salientar que esse pensamento simplificador moderno sustentou toda a aventura ocidental capitalista desde o século XVII, inclusive, ele é um dos principais responsáveis pela forma de como vemos e percebemos a realidade hoje. Essa visão traduziu-se em tecnocentrismo, explorado pelo capitalismo sob a forma de produtos e serviços que vieram atender as necessidades humanas, além de produzir novas necessidades e desejos como forma de impulsionar o sistema fundamentado no crescimento ilimitado. Entretanto, apesar de possibilitar inúmeros progressos, esse modelo se esqueceu de suas consequências nocivas, que só começaram a se revelar a partir de meados do século XX com o agravamento da crise ambiental e das mobilizações da 
sociedade civil por todo o mundo em torno de pautas socioambientais (GLADWIN; KENNELLY; KRAUSE, 1995; MORIN, 2015).

Diante disso, este estudo tem por objetivo apresentar, a partir da análise do discurso dominante de sustentabilidade (de Brundtland), uma proposta alternativa a ele, tendo como perspectiva a Teoria do Pensamento Complexo de Edgar Morin. Destacamos que não temos a pretensão de realizar uma análise fechada e muito menos definitiva, mas apenas discorrer sobre as limitações do pensamento moderno que produz e legitima a disjunção entre a sociedade e natureza. Com base nisso, procuraremos apresentar as possíveis contribuições do Pensamento Complexo em relação à questão da sustentabilidade.

Quanto aos aspectos metodológicos, este estudo foi definido como bibliográficodescritivo-qualitativo: bibliográfico, uma vez que foi realizado com base em materiais já existentes, como, artigos científicos e livros; descritivo, visto que descreveu características de um determinado fenômeno, no caso, a sustentabilidade; e qualitativo, pois seu objetivo foi interpretar significados, não buscando regularidades, mas sim, a compreensão do objeto estudado (SAMPIERI; COLLADO; LUCIO, 2013).

De modo a alcançarmos nossos objetivos, dividimos o artigo em quatro partes. Inicialmente, apresentamos as bases teóricas-conceituais que orientaram o estudo. Em seguida, fazemos uma breve introdução ao Pensamento Complexo na perspectiva de Morin. Por fim, procedemos com as discussões sobre a sustentabilidade complexa, seus avanços e desafios para o discurso de sustentabilidade.

\section{Pensamento Complexo na perspectiva de Edgar Morin}

Segundo Morin (2018), um dos principais desafios do Pensamento Complexo é a necessidade de reconstruir nosso modo de pensar. Temos a necessidade de um pensamento que compreenda e examine os fenômenos de maneira multidimensional, que reconheça a realidade como concomitantemente solidária e conflituosa, que respeite as diferenças, enquanto reconhece a unicidade. Precisamos substituir o pensamento que reduz, isola e separa, por um pensamento que relaciona, distingue e une, substituindo o pensamento disjuntor por um Pensamento Complexo.

O pensamento que une substituirá a causalidade linear e unidirecional por uma causalidade em círculo e multirreferencial; corrigirá a rigidez da lógica clássica pelo diálogo capaz de conceber noções ao mesmo tempo complementares e antagonistas, e completará o conhecimento da 
integração das partes em um todo, pelo reconhecimento da integração do todo no interior das partes. Ligará a explicação à compreensão, em todos os fenômenos humanos (MORIN, 2018, p. 92-93).

O pensamento moderno desconsidera a aparente complexidade dos fenômenos a fim de revelar a ordem simples a que eles obedecem. Reduzindo, separando e limitando o conhecimento ao que é mensurável e quantificável, engendra modos simplificadores que mais mutilam do que retratam as realidades ou os fenômenos de que tratam, transpondo o complexo ao simples. Chega a ser uma inteligência cega, que destrói os conjuntos e as totalidades. Baseando-se na separação entre o objeto e o meio, o pensamento moderno entende que para a compreensão do objeto é necessário isolá-lo, com o objetivo de controlá-lo para conhecê-lo melhor. Já a complexidade opõe-se à simplificação e a redução da realidade. Buscando um saber não fragmentado e não reduzido, ela propõe a integração entre observador e o fenômeno observado, reconhecendo o inacabado e a incompletude de qualquer conhecimento (MORIN; MOIGNE, 2000; MORIN, 2015; 2018). Mas o que é, de fato, a complexidade? Em síntese,

[...] a um primeiro olhar, a complexidade é um tecido (complexus: o que é tecido junto) de constituintes heterogêneos inseparavelmente associados: ela coloca o paradoxo do uno e do múltiplo. Num segundo momento, a complexidade é efetivamente o tecido de acontecimentos, ações, interações, retroações, determinações, acasos, que constituem nosso mundo fenomênico (MORIN, 2015, p. 13).

Para Morin (2015), esse novo modo de pensar não tem por objetivo retomar a ambição do pensamento simplificador de controlar o real. Pelo contrário, seu objetivo é exercer um pensamento capaz de lidar com o real como este se apresenta e com ele dialogar. A complexidade surge onde o pensamento simplificador falha, ela integra e reconhece os modos simplificadores de pensar, contudo, recusa suas visões mutiladoras, reducionistas, unidimensionais que se consideram reflexo da realidade. O Pensamento Complexo aspira um conhecimento multidimensional, animado por um saber não fragmentado e não redutor. Contudo, "a complexidade não é a chave do mundo, mas o desafio a enfrentar; por sua vez o Pensamento Complexo não é o que evita ou suprime o desafio, mas o que ajuda a revelá-lo, e às vezes mesmo a superá-lo" (MORIN, 2015, p. 8). É importante ter a clareza de que complexidade é diferente de complicação. O complicado pode ser decomposto em partes para permitir sua compreensão (princípio da simplificação). Já a complexidade impõe a impossibilidade de simplificar, visto queno complexo se perdem as distinções e clarezas nas identidades e causalidade, onde ações, 
interações, determinações, retroações, incertezas e desordens perturbam o fenômeno através de uma relação paradoxal entre uno e múltiplo (MORIN, 2016).

No pensamento moderno (cartesiano e simplista) as contradições são um sinal de erro. Agora no complexo, as contradições não significam erro, mas sim o atingimento de uma camada mais profunda da realidade. Por isso, a complexidade acolhe as incertezas, as contradições, a incapacidade de formular leis gerais e de conceber uma ordem absoluta. $\mathrm{O}$ complexo nos faz compreender que jamais poderemos nos desprender da incerteza e que jamais conseguiremos ter um saber total. Para a complexidade, a totalidade é a não verdade (MORIN, 2015). De acordo com Morin, "nem mesmo as condições mais singulares, as mais localizadas, as mais particulares, as mais históricas da emergência de uma idéia, de uma teoria, são a prova de sua veracidade. Porque, afinal, há sempre um princípio de incerteza em todo conhecimento, em todo fundo de verdade" (PENA-VEGA; NASCIMENTO, 1999, p. 9). Com base nisso, Edgar Morin apresenta sete princípios para pensar a complexidade. Esses princípios são, concomitantemente, interdependentes e complementares.

(1) Princípio sistêmico: a ideia sistêmica se opõe à ideia reducionista que "o todo é a soma das partes". Para o Complexo, não é possível conhecer o todo sem conhecer as partes, e nem conhecer as partes sem conhecer o todo (MORIN; MOIGNE, 2000; MORIN, 2018). O universo, a humanidade e a Terra são totalidades dinâmicas construídas por redes interconectadas que se envolvem por diversas e múltiplas interconexões, onde cada uma precisa da outra para existir, e coexistir. O propósito desse princípio é religar as partes ao todo (LUZIO-DOS-SANTOS, 2017).

(2) Princípio hologramático: a complexidade acredita que parte e todo são dimensões da mesma realidade (MORIN; MOIGNE, 2000; MORIN, 2018). Assim, "podese enriquecer o conhecimento das partes pelo todo e do todo pelas partes, num mesmo movimento produtor de conhecimentos" (MORIN, 2015, p. 75). Segundo Luzio dos Santos (2007, p. 36), esse princípio amplia a visão holística tradicional, pois "não se limita ao holismo porque não se reduz à soma das partes, mas compreende que cada parte carrega o todo em si”.

(3) Princípio do círculo retroativo: segundo esse princípio, causa e feito são formas não previsíveis e não controláveis no meio e no sistema do qual fazem parte. E, devido ao princípio da incerteza, as mesmas causas podem provocar efeitos diferentes (LUZIO-DOSSANTOS, 2017). Esse princípio rompe com a causalidade linear, em que "a causa age sobre o efeito e o efeito sobre a causa" (MORIN; MOIGNE, 2000).

Rev. Eletrônica Mestr. Educ. Ambient. Rio Grande, v. 37, n. 1, p. 208-227, jan/abr. 2020. E-ISSN 1517-1256 
(4) Princípio do círculo recursivo: ultrapassa a noção de regulação para a de autoorganização e autoprodução. No complexo, nossas relações produzem a sociedade, mas a sociedade, enquanto emergente, produz os indivíduos (MORIN, 2018). Ou seja, "os produtos e os efeitos são ao mesmo tempo, causas e produtores do que os produz" (MORIN, 2015, p. 74).

(5) Princípio da auto-organização: para a complexidade, os seres vivos são autoorganizadores que se autoproduzem ininterruptamente a fim de conservar sua autonomia (MORIN; MOIGNE, 2000). A auto-organização é o processo onde cada sistema cria suas próprias determinações e finalidades (MORIN, 2015). Como o Pensamento Complexo é sempre marcado pelo inacabado, essa característica permite a interação com outros fenômenos, sistemas e matérias. A ordem e o caos se mesclam, num princípio auto organizativo e aberto a novas interações (LUZIO-DOS-SANTOS, 2017).

(6) Princípio dialógico: a complexidade une dois princípios que devem excluir-se um ao outro, mas são indissociáveis numa mesma realidade. Considera as contradições, mas também a complementariedade que é inerente (MORIN; MOIGNE, 2000). Através do princípio dialógico a complexidade mantém a dualidade no seio da unidade, associando, simultaneamente, dois termos complementares e antagônicos (MORIN, 2015).

(7) Princípio da reintrodução do conhecimento em todo conhecimento: parte da ideia que todo o conhecimento é uma reconstrução de outros conhecimentos numa determina cultura e num tempo determinado (MORIN; MOIGNE, 2000). Para a percepção científica, todo conhecimento é uma reconstrução feita por um sujeito, em uma época e cultura determinas. Morin, propõe a reforma desse pensamento, uma nova maneira de organizar o conhecimento. Esse princípio integra diversas idéias, promovendo um intercâmbio entre culturas, regenerando o humanismo, através da emergência de novas humanidades. Seria um modo de pensar, capaz de unir e solidarizar conhecimentos separados, apto a não se fechar no local e no particular, mas de conceber conjuntos (MORIN, 2018).

Portanto, segundo Morin (2015), o complexo é o desafio e não uma resposta. Ele não é um fundamento, mas sim "o princípio regulador que não perde de vista a realidade do tecido fenomênico no qual estamos e que constitui nosso mundo" (MORIN, 2015, p. $105)$. 


\section{Sustentabilidade Complexa}

Nesta seção, discutiremos os principais desafios e contribuições da sustentabilidade complexa como visão alternativa ao discurso dominante de sustentabilidade. Propondo a ampliação das clássicas dimensões do discurso de Brundtland (ambiental, social e econômica), incorporamos mais quatro outras dimensões, entendendo o fenômeno como uma arena aberta e propicia a novas perspectivas que tanto se complementam como podem produzir conflitos num emaranhado de relações de interdependência que Luzio-dos-Santos e Oliveira (2019) chamam de "teia da sustentabilidade" e que inclui além das três dimensões clássicas, social, ambiental e econômica a dimensão espacial, a dimensão política, a dimensão cultural e a dimensão interior.

\section{Principais Desafios}

O modelo de desenvolvimento capitalista, apoiado no tecnocentrismo e fundamentado no pensamento moderno, levou a humanidade a uma grave crise socioambiental, uma crise da relação entre sociedade e natureza. Essa crise "veio questionar a racionalidade e os paradigmas teóricos que impulsionaram e legitimaram o crescimento econômico, negando a natureza" (LEFF, 2001, p. 15). Assim, os primeiros discursos de sustentabilidade surgiram como marcos normativos para se repensar essa racionalidade capitalista e como condição para sobrevivência da humanidade (LEFF, 2001). Segundo Morin (2013), precisamos restaurar a disjunção entre a sociedade e natureza, resultado do pensamento moderno ocidental. Para ele, "O homo sapiens não deve mais tentar dominar a Terra, mas sim zelar por ela e viver nela com responsabilidade" (MORIN, 2013, p. 104).

Percebeu-se que o discurso em torno do desenvolvimento sustentável difundido pelo Relatório de Brundtland é legitimado pela mesma lógica capitalista que deu origem a disjunção sociedade/natureza, pois tomou o crescimento econômico como a condição necessária para erradicar a pobreza, reorientar o uso dos recursos naturais, atender às necessidades humanas e preservar o meio ambiente (PIERRI, 2001; PINHEIRO; VIEIRA, 2018). A ideia de desenvolvimento sustentável tem se mostrado insuficiente para compreender e atender a complexidade dos problemas socioambientais atuais. O mundo é formado por múltiplas relações e interconexões, que demandam respostas multidimensionais e interdisciplinares, que o discurso de sustentabilidade de Brundtland, Rev. Eletrônica Mestr. Educ. Ambient. Rio Grande, v. 37, n. 1, p. 208-227, jan/abr. 2020. E-ISSN 1517-1256 
fundamentado no pensamento moderno (cartesiano e simplista), parece não conseguir responder (BELCHIOR; VIANA, 2017).

O modelo de desenvolvimento capitalista desconsidera as externalidades criadas por ele (devastação ambiental, aquecimento global, poluição de toda ordem, redução da biodiversidade, desemprego, migrações em massa, pobreza, entre outros), nos colocando em uma séria crise (BELCHIOR; VIANA, 2017). Segundo Morin (2013), as soluções para responder a esses problemas não são apenas técnicas, elas necessitam de uma reforma do nosso modo de pensar para englobar a relação sociedade/natureza em sua complexidade e engendrar as mudanças demandas pela sociedade. A complexidade desses problemas abre caminho para "um pensamento da complexidade e a métodos interdisciplinares de investigação, capazes de articular diferentes conhecimentos para abranger as múltiplas relações, causalidades e interdependências que estabelecem processos de diversas ordens de materialidade: física, biológica, cultural, econômica, social” (LEFF, 2006, p. 279).

Desse modo, o Pensamento Complexo surge em resposta ao projeto capitalista de desenvolvimento. Essa reflexão demanda uma reforma no discurso de sustentabilidade, construída sob a perspectiva da sociedade e do meio ambiente, orientada por novos valores e saberes, que articule sem homogeneizar, que respeite as diversidades, que aceite as contradições, e que não se traduza a um discurso simples e reducionista. Portanto, o Pensamento Complexo não deve ser visto como uma resposta à sustentabilidade e sim como o desafio, como uma nova possibilidade de pensar a sustentabilidade, que englobe suas incertezas, suas contradições, suas interações, suas retroações, e que seja capaz de representar a realidade (LEFF, 2001; MORIN, 2015; 2016).

\section{Sustentabilidade e Complexidade}

O discurso de sustentabilidade de Brundtland, legitimado pelo pensamento moderno, vincula o crescimento econômico à proteção ambiental, supondo que o progresso tranquilizaria a sociedade, e que é possível ter tudo o que desejamos sem riscos, recorrendo a uma ilusória sensação de futuro (MILNE; KEARINS; WALTON, 2006). Uma das críticas deste estudo é que o discurso de Brundtland faz uma falsa alusão à integração das três dimensões da sustentabilidade (ambiental, social e econômica), pois, como vimos, ele toma o crescimento econômico (dimensão econômica) como condição necessária para erradicar a pobreza, atender às necessidades humanas e reorientar o uso dos recursos naturais (PINHEIRO; VIEIRA, 2018). Ou seja, na prática, a dimensão econômica sempre 
predomina sobre as duas outras dimensões (ambiental e social), produzindo uma visão não complexa da realidade, visto que considera que há uma realidade superior de um lado (econômica), e outras realidades inferiores de outro (ambiental e social).

Um instrumento que tem apoiado esse discurso é o tecnocentrismo. Nele, o homem tido como superior à natureza e separado dela, tem legitimidade para explorá-la, e o crescimento econômico e a inovação são vistos como justificativas para a dominação da Terra. Segundo essa visão, a natureza é resiliente e os danos gerados são reversíveis, o crescimento populacional é tido como a força criativa para a engenharia das sociedades, e a economia é vista como um sistema linear e isolado da natureza (GLADWIN; KENNELLY; KRAUSE, 1995). Desse modo, o capitalismo, apoiado pela visão tecnocêntrica, produziu mazelas ambientais e sociais com a mesma eficiência com que produziu riquezas. E pior ainda, as externalidades desse sistema (desemprego, desigualdades sociais, problemas ambientais, etc.) foram vistas como inerentes ao próprio sistema, como inconvenientes que seriam mais que compensados pela eficiência do seu modelo desenvolvimentista (SACHS, 2008). Gladwin, Kennelly e Krause (1995) afirmam que o tecnocentrismo é patológico, pois dissocia muitos componentes críticos dos sistemas de suporte à vida, e rompe com as ligações que a sustentabilidade exige, dando origem a desiquilíbrios que ameaçam o futuro de toda a humanidade.

Outro ponto importante é que esse discurso omite, intencionalmente ou não, outras quatro dimensões da sustentabilidade: a política, a cultural, a espacial e a interior. Por isso, sugerimos, com base no estudo de Nascimento (2012) e transversalmente pelo olhar do Pensamento Complexo de Edgar Morin, um novo discurso de sustentabilidade: a sustentabilidade complexa. O termo é decorrente da tentativa de união das dimensões da sustentabilidade e dos princípios do Pensamento Complexo. Para a sustentabilidade complexa, o discurso de sustentabilidade possui sete dimensões (e em aberto): dimensão ambiental, dimensão social, dimensão econômica, dimensão política, dimensão cultural, dimensão espacial e dimensão interior; e tem como princípios norteadores da complexidade: princípio sistêmico, princípio hologramático, princípio do círculo retroativo, princípio do círculo recursivo, princípio da auto-organização, princípio dialógico, e princípio da reintrodução do conhecimento em todo conhecimento (MORIN; MOIGNE, 2000; MORIN, 2015; 2018).

A sustentabilidade complexa não pretende levar o discurso a conclusões finais, mas sim abrir caminhos e ampliar a compreensão, respeitando a diversidade, sem fazer um puro e simples catálogo de dimensões fechadas e definitivas da sustentabilidade (MORIN, Rev. Eletrônica Mestr. Educ. Ambient. Rio Grande, v. 37, n. 1, p. 208-227, jan/abr. 2020. E-ISSN 1517-1256 
2015). A sustentabilidade complexa reconhece as diferentes dimensões como, simultaneamente, solidárias e conflituosas, entrelaçadas como fios que se comunicam indefinidamente e de maneira inseparável, formando um conglomerado de processos e relações, que só assim podem ser adequadamente entendidas. As contradições e embates dessas dimensões não são consideradas excludentes, e sim, complementares, uma influenciando a outra e sendo por esta influenciada (LUZIO-DOS-SANTOS, 2017).

A primeira dimensão da sustentabilidade complexa é a dimensão ambiental. Essa dimensão considera a responsabilidade do homem frente ao meio ambiente, isto é, sua relação com a natureza. Segundo essa visão, a existência do homem está diretamente relacionada com as relações que ele estabelece com a natureza, tanto para sua própria existência, como para a continuidade do planeta (BELCHIOR; VIANA, 2017). De acordo com Leff (2001), as questões ambientais precisam penetrar todas as esferas da consciência e do conhecimento, no campo da política e na construção de uma nova economia. Não se trata apenas de incorporar questões ambientais as atividades econômicas, ou de valorizar os recursos naturais, mas também de fomentar o desenvolvimento de diferentes formas e alternativas de produção em harmonia com a natureza. $\mathrm{O}$ principal objetivo da dimensão ambiental é reapropriar o homem à natureza. Morin (2013, p. 104), afirma que "é preciso salvar a Terra! É preciso salvar nossa Pachamama, nossa Terra mãe! Para nos tornarmos plenamente cidadãos da Terra, é imperativo mudar nosso modo de habitá-la!”.

A segunda dimensão é a social, a qual preocupa-se com a sociedade como todo, e em como a sociedade é afetada pelos diferentes problemas sociais gerados pela atividade capitalista (pobreza, violência, etc.) (LASSU, 2019). Essa dimensão tem por objetivo garantir que todas as pessoas tenham condições iguais de acesso a bens e serviços de qualidade, necessários para uma vida digna (MENDES, 2009). Além disso, busca meios para a redução progressiva dos problemas sociais gerados pela lógica capitalista, que devem ser tratados como indissociáveis e analisados de maneira multidimensional (MORIN, 2013), garantindo melhorias na qualidade de vida das pessoas e a redução das disparidades entre a riqueza e a miséria, bem como o nivelamento de padrão de renda, acesso à educação, alimentação e moradia (GARCIA, 2016). A dimensão social busca satisfazer as necessidades humanas básicas em harmonia com o desenvolvimento da sociedade e do meio ambiente (BELCHIOR; VIANA, 2017).

A terceira dimensão é a econômica. "Com a crise ambiental, a economia se vê obrigada a assumir sua responsabilidade na crescente degradação ecológica e na escassez de recursos naturais" (LEFF, 2010, p.37). Por isso, essa dimensão vem questionar a Rev. Eletrônica Mestr. Educ. Ambient. Rio Grande, v. 37, n. 1, p. 208-227, jan/abr. 2020. E-ISSN 1517-1256 
economia construída sob a base de uma visão antinatureza que foi capaz de produzir, ao mesmo tempo, riquezas e misérias, e que impulsionada pelo lucro, nos conduz ao colapso (MORIN, 2013). A sustentabilidade complexa enfatiza o abandono do crescimento ilimitado, cujo propulsor é a busca do lucro por parte dos detentores do capital e que causa consequências irreversíveis para o meio ambiente e para a humanidade (GARCIA, 2016). Suas idéias abandonam o delírio capitalista de crescimento ilimitado e o substitui por uma economia plural, que ao lado da economia do lucro e do Estado, se constituiria em uma alternativa econômica mais solidária e social. A dimensão econômica coloca a economia em seu devido lugar, como meio, e não como fim último da atividade humana (MORIN, 2013).

A quarta dimensão é a política. Essa dimensão considera a sustentabilidade sobretudo como um projeto político e isto se explicita de duas maneiras. Primeiro, pelo fato de que o discurso de sustentabilidade qualifica o tipo de desenvolvimento almejado para determinada sociedade. Segundo, por determinar a identificação de sujeitos que seriam "responsáveis" pela constituição do referido projeto. Assim, antes de se constituir um desafio teórico, o discurso de sustentabilidade demanda determinação e interesse político, no sentido de restaurar a relação entre sociedade e natureza (SANTOS, 1996 apud MANTOVANELI JR.; SAMPAIO, 2007). Segundo Luzio-dos-Santos (2015), essa dimensão engloba um dos maiores desafios para a sustentabilidade, pois ela tem a função de incorporar

[...] a esfera política e a preocupação com avanços no plano democrático, com aderência a modelos de governança participativa, capazes de criar e aprimorar as instituições sociais, tornando-as mais fortes, transparentes, participativas e representativas dos diferentes interesses da sociedade e dos demais sistema de vida presentes no planeta. O ideal democrático deve transcender o universo estatal e invadir as empresas, sociedade civil e demais esferas que compõem a vida social, e lutar contra os projetos hierárquicos, centralizados, autoritários e personalistas que predominam no mundo atual (LUZIO-DOS-SANTOS, 2015, p. 34).

A quinta dimensão é a cultural. Essa dimensão promove e preserva as tradições e valores culturais regionais/locais de uma determinada coletividade e acompanha as suas transformações, além de assegurar a todos, oportunidades iguais de acesso aos equipamentos culturais da sociedade (MENDES, 2009). Essa dimensão acredita que o conhecimento de diferentes formações sociais e culturais são essenciais para a conservação da natureza, cada um com o seu estilo étnico e forma diversa de significação cultural. Importante ressaltar que a dimensão cultural se opõe a qualquer forma de colonização ou Rev. Eletrônica Mestr. Educ. Ambient. Rio Grande, v. 37, n. 1, p. 208-227, jan/abr. 2020. E-ISSN 1517-1256 
idéia de superioridade cultural, reconhecendo o multiculturalismo e o diálogo de saberes como meios fundamentais para construção de alternativas para a crise que enfrentamos (LEFF, 2010; 2011; LUZIO-DOS-SANTOS, 2015).

A sexta dimensão definida por espacial ou territorial, preocupa-se particularmente com o espaço geográfico, ou seja, como o desenvolvimento é distribuído no espaço, haja vista que a concentração extrema é um dos principais problemas enfrentados pela contemporaneidade. São sintomáticas as migrações em massa, a desertificação de macrorregiões superexploradas, concentração de superpopulações em metrópoles inadministráveis. Tudo isso se reflete em desequilíbrios sistêmicos de proporções superlativas, como o aumento da violência, problemas de mobilidade urbana, favelização e carências de infraestrutura (LUZIO-DOS-SANTOS; OLIVEIRA, 2019).

Além das dimensões já apresentadas, aponta-se uma sétima que compreende a dimensão interior, que se propõe a entender percepções, comportamentos, valores e posicionamentos diante da realidade. Essa abordagem parte do princípio de que somos fruto da realidade que nos cerca, mas também produtores dela. Nossa capacidade de refletir e sentir define valores e comportamentos, que podem se traduzir em potenciais transformadores da realidade. A capacidade de autorreflexão e abertura para compreender e interpretar os fenômenos que nos cercam, é a raiz para um possível despertar para a realidade subjetiva numa experiência que Morin chama de "vida poética", em que se desenvolve a sensibilidade, a empatia e o senso de responsabilidade por tudo e todos numa ideia de unidade no plural (LUZIO-DOS-SANTOS; OLIVEIRA, 2019).

Visto isso, podemos sintetizar as contribuições do discurso de sustentabilidade complexa ao campo discursivo da sustentabilidade. A primeira contribuição é a forma de pensar cada dimensão. Cada dimensão não pode ser analisada de forma isolada ou separada, elas precisam ser analisas em conjunto (conjunção do uno e do múltiplo). Segundo o princípio sistêmico, ambas as dimensões estão interconectas através de múltiplas conexões, onde cada dimensão precisa da outra para existir e coexistir. Para a sustentabilidade complexa, não é possível conhecer o todo (sustentabilidade) sem conhecer as partes (dimensões), e nem conhecer as partes (dimensões) sem conhecer o todo (sustentabilidade). Cada dimensão carrega o todo em si, ou seja, todo e parte fazem parte da mesma realidade (MORIN; MOIGNE, 2000; MORIN, 2015; 2018). Por isso, essas dimensões "devem ser vivenciadas considerando que não existimos, mas coexistimos numa rede de vida feita de elementos interdependentes, em que basta a crise numa das 
partes para comprometer a sustentabilidade do conjunto" (LUZIO-DOS-SANTOS, 2015, p. 34).

A segunda contribuição abrange o princípio do círculo retroativo, do círculo recursivo e da auto-organização. As dimensões, apesar de descritas e detalhadas, não são controláveis. Alterações em uma determinada dimensão pode provocar efeitos diferentes em outra(s). A sustentabilidade complexa rompe com determinismos e com a causalidade linear. Ela considera que, enquanto uma dimensão produz outra, ela é produzida pelas demais, num processo de auto-organização ininterrupto, aberto, que recebe interações do meio, e que abraça o caos e a incerteza (MORIN; MOIGNE, 2000; MORIN, 2015; 2018).

A terceira contribuição aborda o princípio dialógico e o princípio da reintrodução do conhecimento em todo conhecimento. A complexidade une dimensões contraditórias, que a princípio se excluem, e as considera indissociáveis. Como, por exemplo, a dimensão ambiental e a dimensão econômica. Para essa perspectiva, não há como crescer economicamente desconsiderando a preservação ambiental. O complexo une interesses contraditórios, dialogando com eles, considerando-os complementares e não concorrentes. Além disso, a sustentabilidade complexa não busca respostas somente na ciência clássica, essa dialogicidade abre caminho para a integração de novas idéias, culturas e conhecimentos populares ao discurso, considerando o diálogo entre os saberes, uma estratégia fundamental para a construção de alternativas para a crise que enfrentamos. É importante frisar que a complexidade não desconsidera o conhecimento científico, apenas não o considera como o único capaz de explicar e orientar o fenômeno da sustentabilidade (MORIN; MOIGNE, 2000; LEFF, 2010; MORIN, 2015; 2018).

Como quarta contribuição, a sustentabilidade complexa apresenta uma proposta alternativa ao discurso dominante de sustentabilidade, propondo um pensamento fora dos muros levantados pelo ocidentalocentrismo capitalista. Sem a pretensão de levar o discurso à sua conclusão, sua intenção é realizar um discurso multidimensional não totalitário, não doutrinário e aberto para a incerteza e a superação, consciente que ele jamais será totalmente fechado e fadado a repetir generalidades (MORIN, 2013; 2015). Sua idéia é promover as bases para a construção de um discurso mais sustentável, ambientalmente equilibrado, economicamente e socialmente justo, politicamente democrático, e culturalmente plural.

Por fim, apesar de suas contribuições, precisamos reconhecer que o paradigma da complexidade possui algumas limitações e encontra também muitas críticas. A complexidade apresenta muita dificuldade ao tentar instituir seu método epistemológico, Rev. Eletrônica Mestr. Educ. Ambient. Rio Grande, v. 37, n. 1, p. 208-227, jan/abr. 2020. E-ISSN 1517-1256 
pois além de sua proposta não ser de fácil compreensão, ela possui carências de fundamentação empírica e de métodos mais claros para seu alcance. Outras posições apontam que ela tende ao relativismo ao tentar conciliar forças e propostas distintas, indo a um plano imaginário, acreditando na possibilidade convivência pacífica entre interesses explicitamente contraditórios (ANDRADE, 2007; SANTOS; PELOSI; OLIVEIRA, 2012). Contudo, apesar de suas limitações, a Teoria do Pensamento Complexo

[...] rompe com várias posturas da modernidade, principalmente no que se refere à busca de certezas e de uma verdade absoluta [...]. No entanto, para nossas mentes acostumadas a verdades e soluções definitivas, a proposta da complexidade pode, num primeiro momento, parecer um tanto relativista, uma vez que não parte de nenhuma ideia de "estado final das coisas", ou mesmo de uma proposta concreta e de fácil apreensão para superar as mazelas da sociedade contemporânea (SANTOS; PELOSI; OLIVEIRA, 2012, p. 68).

\section{Considerações Finais}

Este artigo teve por objetivo apresentar, a partir da análise do discurso dominante de sustentabilidade, uma proposta alternativa a ele, tendo como perspectiva a Teoria do Pensamento Complexo de Edgar Morin. O ponto de partida do estudo foi a inquietação frente aos problemas engendrados pelo modelo de desenvolvimento capitalista, que conduziu a humanidade a infinitas tragédias e nos conduz a um colapso global. Diante dessa situação, vimos que o discurso de sustentabilidade surgiu em resposta à crescente preocupação da sociedade com os problemas socioambientais globais, e como tentativa de buscar uma melhor compreensão da realidade e de se posicionar de maneira sustentável diante dela. $\mathrm{O}$ discurso de sustentabilidade mais aceito e adotado em todo o mundo foi o discurso de Brundtland (1987). Esse discurso tentou conciliar a preservação do meio ambiente e o desenvolvimento econômico, contudo, foi legitimado pela mesma lógica capitalista que deu origem aos inúmeros problemas atuais, por isso, tem se mostrado insuficiente para compreender a complexidade da realidade.

A sociedade começa a demandar uma resposta frente ao projeto de desenvolvimento capitalista. Uma resposta capaz de englobar a proteção ambiental e social, repensar a relação sociedade e natureza, e recepcionar a sua complexidade, visto que o atual modelo de desenvolvimento desconsiderou as externalidades geradas por ele (devastação ambiental, aquecimento global, poluição de toda ordem, redução da biodiversidade, desemprego, pobreza, entre outros), colocando-nos em uma série crise 
socioambiental. Nesse contexto, o Pensamento Complexo surge com o desafio de instituir outra forma de enxergar o mundo e a natureza, através da superação do pensamento moderno (cartesiano e simplista), que apoiado pelo tecnocentrismo, deu base para toda aventura ocidental capitalista. O Pensamento Complexo não deve ser visto como uma resposta à sustentabilidade e sim como o desafio; como uma nova possibilidade de pensar os desafios que a permeiam. De acordo com Morin (2013), as soluções para responder aos problemas socioambientais não são apenas técnicas, elas necessitam de uma reforma do nosso modo de pensar para englobar a relação sociedade/natureza em sua complexidade e engendrar as mudanças demandas pela nossa sociedade.

Após a revisão teórico-conceitual, apresentamos o discurso de sustentabilidade complexa. Uma proposta alternativa desenvolvida da união das dimensões da sustentabilidade e dos princípios do Pensamento Complexo. A sustentabilidade complexa propõe ampliar as clássicas dimensões do discurso do Brundtland (ambiental, social e econômica) incorporando quatro outras dimensões ao discurso: a dimensão política, a dimensão cultural, a dimensão espacial e a dimensão interior. Sua proposta não tem a pretensão de levar o discurso de sustentabilidade à conclusão, e sim realizar uma análise multidimensional, aberta para a incerteza e a superação, consciente que ela jamais será fechada e fadada a repetir generalidades. A proposta busca romper com várias posições da modernidade, visto que não busca certezas, contrariando muitas posições pragmáticas. Ou seja, ela não se limita aos efeitos práticos e de valor utilitário, mas sim ao potencial reformador e reflexivo de suas proposições.

Apesar de não exaustivo e com limitações, como a falta de verificação empírica, este estudo tem um papel muito importante para o campo de estudos da sustentabilidade. Ele contribui com um novo discurso, ampliando os debates, possibilitando novos enfoques, novas perspectivas e novas abordagens sobre a temática. Que a partir deste estudo, novos espaços sejam abertos para futuras pesquisas teóricas e experimentais mais pontuais sobre o Pensamento Complexo e as questões que permeiam a sustentabilidade.

\section{Referências}

ANDRADE, Érico. Uma crítica à teoria da complexidade proposta por Edgar Morin. Revista Dissertatio de Filosofia, Pelotas, v. 26, p. 167-187. 2007. Disponível em: https://periodicos.ufpel.edu.br/ojs2/index.php/dissertatio/article/view/8895. Acesso em: 11 nov. 2019. 
BALIM, Ana Paula Cabral; MOTA, Luiza Rosso; SILVA, Maria Beatriz Oliveira da. Complexidade ambiental: o repensar da relação homem-natureza e seus desafios na sociedade contemporânea. Veredas do Direito, Belo Horizonte, v. 11, n. 21, p. 163-186, jan./jun. 2014. Disponível em:

http://revista.domhelder.edu.br/index.php/veredas/article/viewFile/410/402. Acesso em: 11 set. 2019.

BELCHIOR, Germana Parente Neiva; VIANA, Iasna Chaves. Sustentabilidade e Meio ambiente: reflexões sob o olhar da complexidade. Amazon's Research and

Environmental Law, v. 4, n. 1, p. 72-90, fev. 2017. Disponível em: http://faar.edu.br/portal/revistas/ojs/index.php/arel-faar/article/download/183/152/0. Acesso em: 3 set. 2019.

CRUTZEN, Paul Josef. Geology of mankind. Nature, London, v. 415, p. 23, jan. 2002.

DOVERS, Stephen R. Sustainability: Demands on Policy. Journal of Public Policy, v. 16, n. 3, p. 303-318, set./dez. 1996.

GARCIA, Denise Schmitt Siqueira. Dimensão Econômica da Sustentabilidade: uma análise com base na economia verde e a teoria do decrescimento. Veredas do Direito, Belo Horizonte, v. 13, n. 25, p. 133-153, jan./abr. 2016. Disponível em: http://revista.domhelder.edu.br/index.php/veredas/article/view/487. Acesso em: 6 set. 2019.

GLADWIN, Thomas N.; KENNELLY, James J.; KRAUSE, Tara-Shelomith. Shifting paradigms for sustainable development: implications for management theory and research. Academy of Management Review, v. 20, n. 4, p. 874-907. 1995. Disponível em: https://www.jstor.org/stable/258959. Acesso em: 01 out. 2019.

HOPWOOD, Bill; MELLOR, Mary; O'BRIEN, Geoff. Sustainable Development: Mapping Different Approaches. Sustainable Development, Newcastle on Tyne, v. 13, n. 1, p. 3852, fev. 2005. Disponível em: https://doi.org/10.1002/sd.244. Acesso em: 03 set. 2019.

LASSU. Laboratório de Sustentabilidade da USP (São Paulo). Pilares da Sustentabilidade. 2019. Disponível em: http://www.lassu.usp.br/sustentabilidade/pilaresda-sustentabilidade. Acesso em: 14 set. 2019.

LEFF, Enrique. Saber ambiental: sustentabilidade, racionalidade, complexidade, poder. Tradução de Lúcia M. E. Orth. Petrópolis: Vozes, 2001.

LEFF, Enrique. Racionalidade ambiental: a reapropriação social da natureza. Tradução de Luís Carlos Cabral. Rio de Janeiro: Civilização Brasileira, 2006.

LEFF, Enrique. Discursos Sustentáveis. Tradução de Silvana Cobucci Leite. São Paulo: Cortez, 2010.

LUZIO-DOS-SANTOS, Luís Miguel. Conexões e perspectivas. In: LUZIO-DOSSANTOS, Luís Miguel. Pautas para outra sociabilidade. Londrina: Eduel, 2015.

LUZIO-DOS-SANTOS, Luís Miguel. Pensamento complexo. Londrina, 2017. No prelo.

Rev. Eletrônica Mestr. Educ. Ambient. Rio Grande, v. 37, n. 1, p. 208-227, jan/abr. 2020. E-ISSN 1517-1256 
LUZIO-DOS-SANTOS, Luís Miguel; OLIVEIRA, Bernardo Carlos Spaulonci Chiachia Matos de. Sustentabilidade Integradora: nas tramas da complexidade. Londrina, 2019. No prelo.

MANTOVANELI JR., Oklinger; SAMPAIO, Carlos Alberto Cioce. Sustentabilidade política e administrativa: contribuições para a reformulação da agenda para o ecodesenvolvimento. Revista de Gestão Social e Ambiental, Recife, v. 1, n. 2, p. 3-21. 2007. Disponível em: https://rgsa.emnuvens.com.br/rgsa/article/view/20. Acesso em: 21 set. 2019.

MENDES, Jefferson Marcel Gross. Dimensões da Sustentabilidade. Revista das Faculdades Santa Cruz, Curitiba, v. 7, n. 2, p. 49-59, jul./dez. 2009. Disponível em: http://www.santacruz.br/v4/download/revista-academica/13/cap5.pdf. Acesso em: 10 out. 2019.

MILNE, Markus J.; KEARINS, Kate; WALTON, Sara. Creating adventures in wonderland: The journey metaphor and environmental sustainability. Organization, v. 13, n. 6, p. 801-839. 2006. Disponível em: http://ww.intergon.net/phd/Milne-Kierens-WaltonCreating AdventuresInWonderland.pdf. Acesso em: 20 set. 2019.

MOORE, Jason W. The Capitalocene, Part I: on the nature and origins of our ecological crisis. The Journal of Peasant Studies, v. 44, n. 3, p. 594-630. 2017. Disponível em: https://doi.org/10.1080/03066150.2016.1235036. Acesso em: 02 set. 2019.

MORIN, Edgar. A via para o futuro da humanidade. Tradução de Edgard de Assis Carvalho, Mariza Perassi Bosco. Rio de Janeiro: Bertrand, 2013.

MORIN, Edgar. Introdução ao Pensamento Complexo. 5. ed. Tradução de Eliane Lisboa. Porto Alegre: Sulina, 2015.

MORIN, Edgar. O método 1: a natureza da natureza. 3. ed. Tradução de Ilana Heineberg. Porto Alegre: Sulina, 2016.

MORIN, Edgar. A cabeça bem-feita: repensar a reforma, reformar o pensamento. 24. ed. Tradução de Eloá Jacobina. Rio de Janeiro: Bertrand, 2018.

MORIN, Edgar; MOIGNE, Jean-Louis Le. A inteligência da complexidade. Tradução de Nurimar Maria Falci. São Paulo: Petrópolis, 2000.

NASCIMENTO, Elimar Pinheiro do. Trajetória da sustentabilidade: do ambiental ao social, do social ao econômico. Estudos Avançados, São Paulo, v. 26. n. 74, p. 51-64. 2012. Disponível em: http://www.scielo.br/pdf/ea/v26n74/a05v26n74.pdf. Acesso em: 15 set. 2019.

PENA-VEGA, Alfredo; NASCIMENTO, Elimar Pinheiro do (Org.). O pensamento complexo: Edgar Morin e a crise da modernidade. Rio de Janeiro: Garamond, 1999. 
PIERRI, Naína. El proceso histórico y teórico que conduce a la propuesta del desarrollo sustentable. In: PIERRI, Naína; FOLADORI, Guillermo (Orgs.) Sustentabilidad?

Desacuerdos sobre eldesarrollosustentable. Montevideo: Trabajo y Capital, 2001.

PINHEIRO, Maria Lenir Rodrigues; VIEIRA, Ricardo Stanziola. O desenvolvimento sustentável no combate à pobreza e à exclusão social. Justiça do Direito, Passo Fundo, v. 32, n. 2, p. 301-317, mai./ago. 2018. Disponível em: http://www.seer.upf.br/index.php/r jd/article/view/6973. Acesso em: 22 set. 2019.

SACHS, Ignacy. Desenvolvimento: includente, sustentável e sustentado. Rio de Janeiro: Garamond, 2008.

SANTOS, Luís Miguel Luzio dos; PELOSI, Edna Marta; OLIVEIRA, Bernardo Carlos Spaulonci Chiachia Matos de. Teoria da Complexidade e as múltiplas abordagens para compreender a realidade social. Serviço Social em Revista, Londrina, v. 14, n. 2, p. 47-72, jan/jun. 2012. Disponível em: http://www.uel.br/revistas/uel/index.php/ssrevista/article/vie w/11823. Acesso em: 01 out. 2019.

SAMPIERI, Roberto Hernández; COLLADO, Carlos Fernández; LUCIO, María del Pilar Baptista. Metodologia de Pesquisa. 5. ed. Tradução de Daisy Vaz de Moraes. Porto Alegre: Penso Editora, 2013. 